\title{
Rekomendasi penerimaan judul skripsi dengan metode simple addative weighting pada sistem informasi skripsi dan tugas akhir Jurusan Teknik Elektro Universitas Negeri Malang
}

\author{
Fauzan C. A. Arifin ${ }^{1}$, Aji Prasetya Wibawa², Utomo Pujianto ${ }^{3}$ \\ 1. Universitas Negeri Malang, Indonesia | fauzancahya16@gmail.com \\ 2. Universitas Negeri Malang, Indonesia | aji.prasetya.ft@um.ac.id \\ 3. Universitas Negeri Malang, Indonesia | utomo.pujianto.ft@um.ac.id
}

\begin{abstract}
Abstrak
Penerimaan judul skripsi merupakan tahap penting dalam penyelesaian skripsi. Dalam tahap tersebut diberikan keputusan diterima, direvisi atau ditolak terhadap judul skripsi yang diajukan mahasiswa. Sistem Pengambilan Keputusan (SPK) menggunakan metode Simple Additive Weighting (SAW) digunakan untuk menyelesaikan masalah tidak terstruktur secara sederhana sehingga dapat melakukan proses pengambilan keputusan yang efektif. Pada artikel ini akan dibahas tentang penerapan metode SAW untuk merekomendasikan keputusan penerimaan judul skripsi pada SPK rekomendasi penerimaan judul skripsi. Kriteria-kriteria yang dibutuhkan dalam rekomendasi penerimaan judul skripsi yaitu kebaruan, batas waktu penelitian, akses terhadap data, sumbangan hasil penelitian, dan kesesuaian topik dengan KBK.
\end{abstract}

\section{Kata Kunci}

Penerimaan Judul Skripsi, Sistem Pendukung Keputusan, Simple Additive Weighting

TEKNO Vol. 28 Issue 1, p94-102 | Jurusan Teknik Elektro, Universitas Negeri Malang, Indonesia | Maret 2018

Fauzan C. A. Arifin, Aji Prasetya Wibawa, Utomo Pujianto | Rekomendasi penerimaan judul skripsi dengan metode simple... 


\section{TEKNO Jumal Teknologi Elekrro dan Kejuruan}

http://journal2.um.ac.id/index.php/tekno | ISSN 1693-8739

\section{Pendahuluan}

Skripsi merupakan karangan ilmiah yang wajib ditulis oleh mahasiswa sebagai persyaratan akhir pendidikan akademisnya. Dalam penyelesaian skripsi terdapat beberapa tahapan, salah satu yang paling penting adalah penerimaan judul skripsi (Wahyudi, 2016). Penerimaan judul skripsi merupakan tahap pemberian keputusan diterima, direvisi atau ditolak terhadap judul skripsi yang diajukan mahasiswa. Setiap dosen memiliki pendapat masing-masing dalam mengambil keputusan penerimaan judu (Waspodo, 2015). Maka dari itu keputusan penerimaan judul bersifat kurang objektif ketika tahap penerimaan judul dilakukan secara manual (Nash, 2003). Selain itu, karena kesibukan dosen maka diperlukan waktu yang cukup lama untuk menghasilkan keputusan penerimaan judul. Hal tersebut juga dapat menurunkan motivasi mahasiswa dalam menyelesaikan skripsi.

Mengenai pentingnya penerimaan judul skripsi serta permasalahan yang dihadapi maka perlu dirancang sebuah Sistem Pendukung Keputusan (SPK) yang dapat membantu penerimaan judul skripsi (Darmawan, 2013; Fishburn, 1967).

\section{Metode}

Sistem pendukung keputusan yang dikembangkan dibutuhkan masukan nilai dari tiga user sesuai kriteria yang ada untuk mendapatkan hasil keputusan penerimaan judul skripsi (Wahono, 2006). Alur sistem dapat dilihat pada Gambar 1.

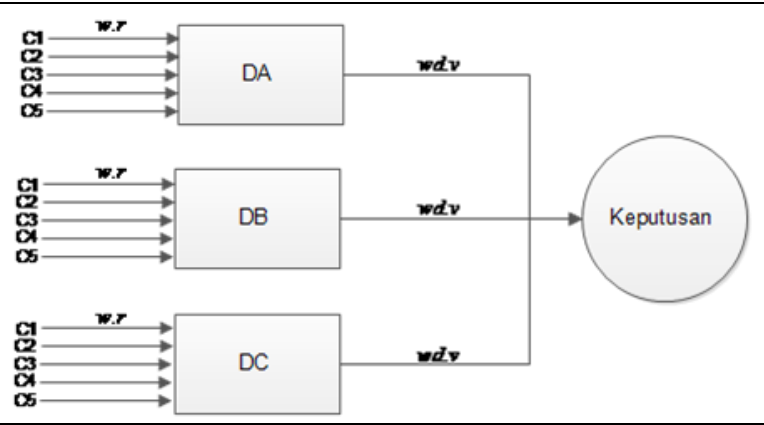

Gambar 1. Alur Kerja Sistem Pendukung Keputusan Penerimaan Judul Skripsi (Indrawaty,2011)

Pemodelan metode SAW menjelaskan tahapan prosedural dalam menerapkan metode SAW pada penerimaan judul skripsi (Darmastuti, 2013). Secara garis besar metode SAW memiliki lima langkah, meliputi (a) menentukan kriteria; (b) menentukan bobot masing-masing kriteria; (c) memberikan nilai judul skripsi; (e) menentukan bobot masing-masing dosen; (d) rekomendasi penerimaan judul (Indrawati, 2011). Pemodelan metode SAW dapat dilihat pada Gambar 2. 


\section{TEKNO Jumal Teknologi Elekrio dan Kejuruan}

http://journal2.um.ac.id/index.php/tekno | ISSN 1693-8739

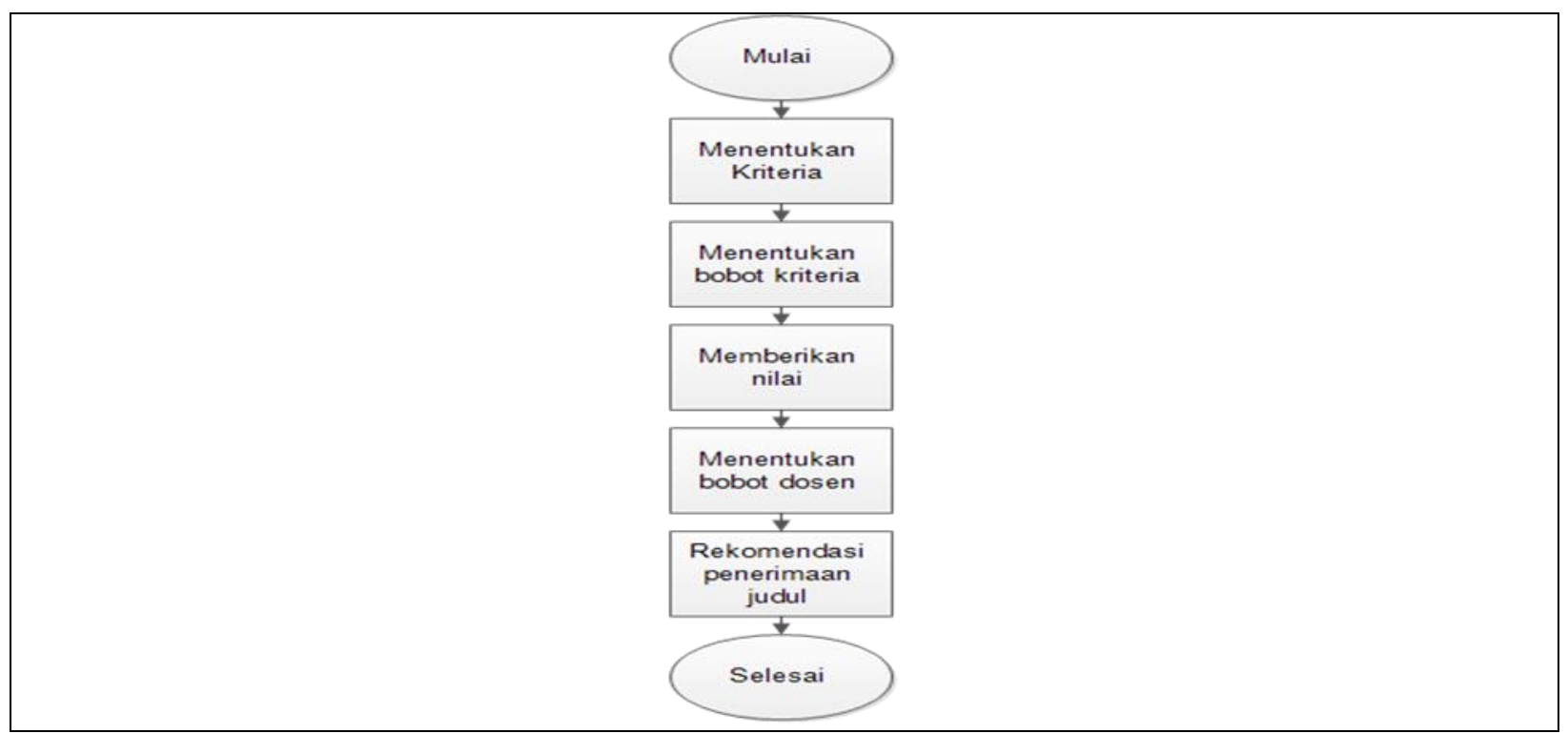

Gambar 1. Tahapan Klasifikasi Dokumen

\section{Menentukan Kriteria (C)}

Penentuan kriteria dilakukan dengan menyebar angket kepada para dosen anggota KBK . Kegiatan penyebaran angket dilakukan untuk mendapatkan bobot awal kriteria dan mendapatkan saran kriteria lain dari responden (Firdausa, 2015). Dari hasil angket didapatkan satu kriteria baru yaitu kesesuaian topik dengan KBK.

Terdapat lima kriteria untuk dijadikan pertimbangan dalam penerimaan judul skripsi yaitu (1) kebaruan (C1); (2) batas waktu penelitian (C2); (3) akses terhadap data (C3); (4) sumbangan hasil penelitian (C4); (5) Kesesuaian topik dengan KBK (C5).

\section{Menentukan Bobot Masing-Masing Kriteria (W)}

Penentuan bobot dilakukan dengan memberi skala 1-10 untuk masing-masing bobot. Kriteria yang memiliki prioritas lebih utama akan diberikan nilai lebih tinggi dibandingkan kriteria lain (Kendall, 2011). Proses pembobotan pada sistem dilakukan oleh user misalnya Ketua Jurusan, sehingga bobot bersifat dinamis. Dengan kata lain setiap KBK memiliki prioritas kriteria yang berbeda-beda dalam penerimaan judul skripsi. Berikut ini contoh pemberian bobot kriteria penerimaan judul.

Tabel 1. Tabel Contoh Nilai Bobot Kriteria

\begin{tabular}{lll}
\hline Kriteria $(\mathrm{C})$ & Keterangan & Bobot (W) \\
\hline C1 & Kebaruan & 7 \\
C2 & Batas Waktu Penelitian & 8 \\
C3 & Akses Terhadap Data & 7 \\
C4 & Sumbangan Hasil Penelitian & 9 \\
C5 & Kesesuaian Topik dengan KBK & 8 \\
\hline Bobot & & 39
\end{tabular}

TEKNO Vol. 28 Issue 1, p94-102 | Jurusan Teknik Elektro, Universitas Negeri Malang, Indonesia | Maret 2018

Fauzan C. A. Arifin, Aji Prasetya Wibawa, Utomo Pujianto | Rekomendasi penerimaan judul skripsi dengan metode simple... 


\section{TEKNO Jumal Teknologi Elekrto dan Kejuruan}

http://journal2.um.ac.id/index.php/tekno | ISSN 1693-8739

Setelah didapatkan nilai bobot dari masing-masing kriteria, kemudian dilakukan proses normalisasi agar bobot bersifat normal dan tidak memiliki kesenjangan terlalu tinggi (Kurniasih, 2013). Dari hasil normalisasi akan digunakan untuk tahap selanjutnya. Berikut adalah persamaan untuk menormalisasi bobot masing-masing kriteria.

$$
\text { Bobot Ternormalisasi }=\frac{B o b o t}{\sum B o b o t}
$$

Hasil normalisasi nilai bobot pada tiap kriteria disajikan pada Tabel 2.

Tabel 2. Tabel Nilai Bobot Kriteria Ternormalisasi

\begin{tabular}{cc}
\hline Kriteria $(\mathrm{C})$ & Bobot Ternormalisasi $(\mathrm{w})$ \\
\hline C1 & 0.179 \\
C2 & 0.205 \\
C3 & 0.179 \\
C4 & 0.231 \\
C5 & 0.205 \\
\hline Jumlah & 1.000 \\
\hline
\end{tabular}

\section{Memberikan Nilai Judul Skripsi}

Pemberian nilai dilakukan dengan memberi skala 1-100 untuk masing-masing kriteria. Selanjutnya nilai yang dimasukkan dikalikan dengan hasil normalisasi bobot kriteria kemudian dijumlahkan untuk mendapatkan nilai judul skripsi (v) dari setiap dosen (Munandar, 2015). Tahap ini dilakukan oleh user yaitu ketua KBK dan dua dosen anggota KBK untuk setiap judul yang masuk ke KBK terkait. Berikut ini contoh pemberian nilai judul skripsi.

Tabel 3. Tabel Contoh Penilaian Judul Skripsi dari Dosen A

\begin{tabular}{clc}
\hline Kriteria $(\mathrm{C})$ & \multicolumn{1}{c}{ Keterangan } & Nilai $(\mathrm{r})$ \\
\hline C1 & Kebaruan & 80 \\
C2 & Batas Waktu Penelitian & 70 \\
C3 & Akses Terhadap Data & 80 \\
C4 & Sumbangan Hasil Penelitian & 60 \\
C5 & Kesesuaian Topik dengan KBK & 95 \\
\hline
\end{tabular}

Tabel 4. Tabel Contoh Penilaian Judul Skripsi dari Dosen B

\begin{tabular}{clc}
\hline Kriteria $(\mathrm{C})$ & Keterangan & Nilai $(r)$ \\
\hline C1 & Kebaruan & 90 \\
C2 & Batas Waktu Penelitian & 80 \\
C3 & Akses Terhadap Data & 80 \\
C4 & Sumbangan Hasil Penelitian & 60 \\
C5 & Kesesuaian Topik dengan KBK & 95 \\
\hline
\end{tabular}

Tabel 5. Tabel Contoh Penilaian Judul Skripsi dari Dosen C

\begin{tabular}{clc}
\hline Kriteria $(\mathrm{C})$ & \multicolumn{1}{c}{ Keterangan } & Nilai $(\mathrm{r})$ \\
\hline C1 & Kebaruan & 50 \\
C2 & Batas Waktu Penelitian & 60 \\
C3 & Akses Terhadap Data & 70 \\
C4 & Sumbangan Hasil Penelitian & 60 \\
C5 & Kesesuaian Topik dengan KBK & 80 \\
\hline
\end{tabular}

TEKNO Vol. 28 Issue 1, p94-102 | Jurusan Teknik Elektro, Universitas Negeri Malang, Indonesia | Maret 2018

Fauzan C. A. Arifin, Aji Prasetya Wibawa, Utomo Pujianto | Rekomendasi penerimaan judul skripsi dengan metode simple... 


\section{TEKNO Jumal Teknologi Elektro dan Kejuruon}

http://journal2.um.ac.id/index.php/tekno | ISSN 1693-8739

Hasil akhir berupa nilai judul skripsi didapatkan dengan persamaan berikut.

Keterangan

$$
\mathrm{v}=\sum w \cdot r
$$

$v=$ Nilai judul skripsi

$\mathbf{w}=$ bobot ternormalisasi masing-masing kriteria

$r=$ nilai masing-masing kriteria

$v_{a}=(80 \times 0.179)+(70 \times 0.205)+(80 \times 0.179)+(60 \times 0.231)+(95 \times 0.205)=76.33$

$v_{b}=(90 \times 0.179)+(80 \times 0.205)+(80 \times 0.179)+(60 \times 0.231)+(95 \times 0.205)=80.16$

$v_{c}=(50 \times 0.179)+(60 \times 0.205)+(70 \times 0.179)+(60 \times 0.231)+(80 \times 0.205)=64.04$

Desain antarmuka proses di atas dapat dilihat pada Gambar 3.

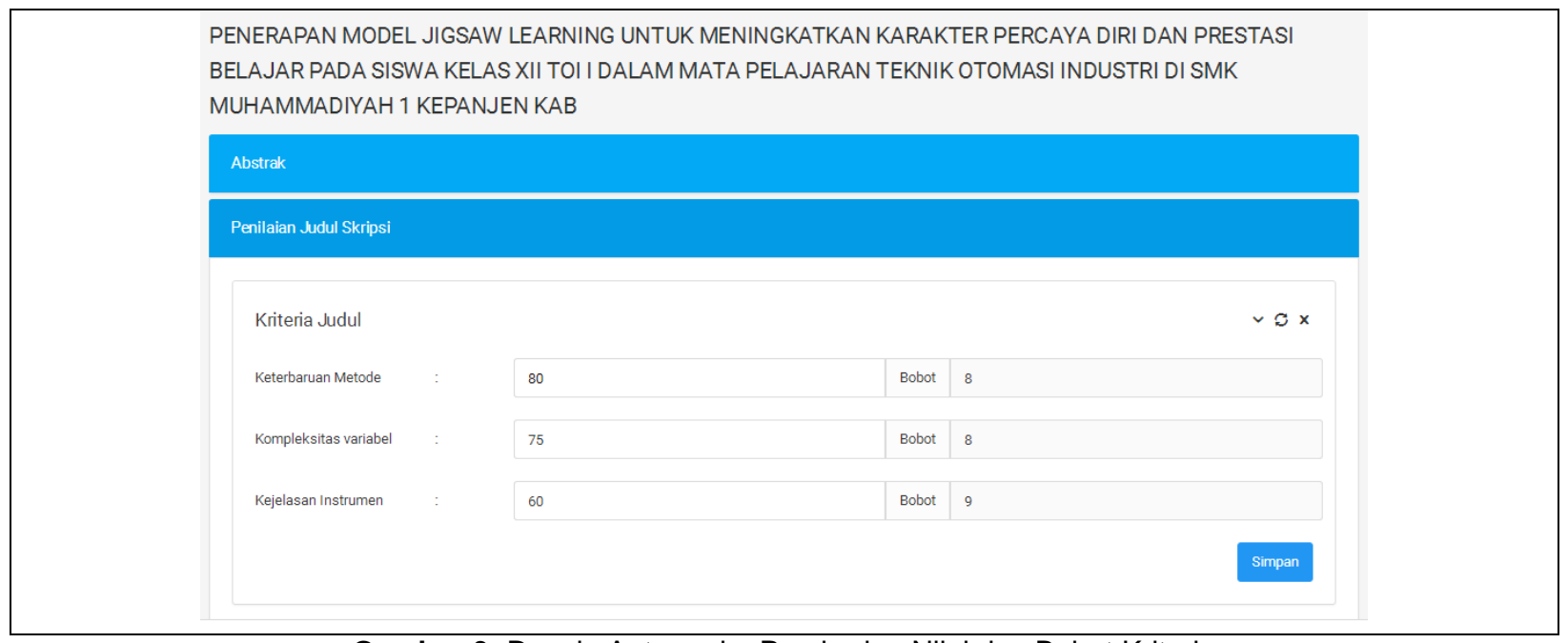

Gambar 3. Desain Antarmuka Pemberian Nilai dan Bobot Kriteria

\section{Menentukan Bobot Masing-Masing Dosen}

Penentuan bobot dosen dilakukan dengan memberi skala 10 dan 8 untuk masing-masing bobot dosen (Mutaqin, 2016). Ketua KBK mempunyai prioritas tertinggi sehingga memiliki bobot 10 sementara dosen anggota KBK memiliki bobot 8. Proses pembobotan dilakukan oleh sistem. Berikut ini contoh pemberian bobot dosen.

Tabel 6. Tabel Contoh Bobot Dosen

\begin{tabular}{lll}
\hline Dosen $(\mathrm{D})$ & Keterangan / Jabatan & Bobot $(\mathrm{Wd})$ \\
\hline DA & Ketua KBK & 10 \\
DB & Dosen Anggota KBK & 8 \\
DC & Dosen Anggota KBK & 8 \\
\hline$\sum$ Bobot & & 26 \\
\hline
\end{tabular}

TEKNO Vol. 28 Issue 1, p94-102 | Jurusan Teknik Elektro, Universitas Negeri Malang, Indonesia | Maret 2018

Fauzan C. A. Arifin, Aji Prasetya Wibawa, Utomo Pujianto | Rekomendasi penerimaan judul skripsi dengan metode simple... 


\section{TEKNO Jumal Teknologi Elekrto dan Kejuruan}

http://journal2.um.ac.id/index.php/tekno | ISSN 1693-8739

Setelah didapatkan nilai bobot dari masing-masing kriteria, kemudian dilakukan proses normalisasi agar bobot bersifat normal dan tidak memiliki kesenjangan terlalu tinggi (Sparague, 1993). Dari hasil normalisasi akan digunakan untuk tahap selanjutnya. Berikut adalah persamaan untuk menormalisasi bobot masing-masing kriteria (Sutikno, 2010).

$$
\text { Bobot Ternormalisasi }=\frac{B o b o t}{\sum B o b o t}
$$

Hasil normalisasi nilai bobot dosen disajikan pada Tabel 7.

Tabel 7. Tabel Nilai Bobot Dosen Ternormalisasi

\begin{tabular}{cc}
\hline Dosen (D) & Bobot (wd) \\
\hline DA & 0.38 \\
DB & 0.31 \\
DC & 0.31 \\
\hline Bobot & 1.00 \\
\hline
\end{tabular}

\section{Rekomendasi Penerimaan Judul}

Rekomendasi penerimaan judul berupa keputusan ditolak, direvisi dan diterima (Pressman, 2010). Keputusan tersebut dihasilkan dari pengelompokan nilai akhir judul skripsi (V) yaitu (1) Ditolak (1-60); (2) Direvisi (60-75); (3) Diterima (75-100). Nilai tersebut dihasilkan dari perkalian bobot dosen ternormalisasi dengan nilai judul skripsi dari setiap dosen melalui persamaan berikut (Morton, 1970).

Keterangan

$$
\mathrm{V}=\sum w d . v
$$

$\mathrm{V} \quad=$ nilai akhir judul skripsi

wd = bobot ternormalisasi masing-masing dosen

$\mathrm{v} \quad=$ nilai judul skripsi

$V=(76.33 \times 0.38)+(80.16 \times 0.31)+(64.04 \times 0.31)=73.73$

\section{Direvisi.}

Dari nilai yang dihasilkan maka keputusan rekomendasi penerimaan judul adalah

\section{Hasil}

Dilakukan pengujian sistem pendukung keputusan penerimaan judul skripsi dengan memberikan penilaian terhadap judul yang diajukan. Pada Tabel 8 dapat dilihat hasil pengujian sistem tersebut. 


\section{TEKNO Jumal Teknologi Elekrto dan Kejuruan}

http://journal2.um.ac.id/index.php/tekno | ISSN 1693-8739

Tabel 8. Hasil Pengujian Sistem Pendukung Keputusan Penerimaan Judul Skripsi

\begin{tabular}{|c|c|c|c|c|c|c|}
\hline No. & $\begin{array}{l}\text { Nilai } \\
\text { Dosen } \\
\text { A }\end{array}$ & $\begin{array}{l}\text { Nilai } \\
\text { Dosen } \\
\text { B }\end{array}$ & $\begin{array}{l}\text { Nilai } \\
\text { Dosen } \\
\text { C }\end{array}$ & Nilai Akhir & Rekomendasi & Rekomendasi Sistem \\
\hline 1 & 76 & 80 & 64 & 73 & Direvisi & Direvisi \\
\hline 2 & 71 & 75 & 77 & 74 & Direvisi & Diterima \\
\hline 3 & 67 & 66 & 74 & 69 & Direvisi & Direvisi \\
\hline 4 & 77 & 79 & 78 & 78 & Diterima & Diterima \\
\hline 5 & 71 & 73 & 71 & 72 & Direvisi & Direvisi \\
\hline 6 & 58 & 56 & 59 & 58 & Ditolak & Ditolak \\
\hline 7 & 67 & 70 & 79 & 71 & Direvisi & Direvisi \\
\hline 8 & 80 & 70 & 75 & 75 & Diterima & Diterima \\
\hline 9 & 65 & 80 & 80 & 74 & Direvisi & Diterima \\
\hline $\begin{array}{l}\cdots \\
100\end{array}$ & 70 & 90 & 65 & $\begin{array}{l}\ldots \\
74\end{array}$ & $\begin{array}{l}\text {... } \\
\text { Direvisi }\end{array}$ & $\begin{array}{l}\ldots \\
\text { Direvisi }\end{array}$ \\
\hline
\end{tabular}

Desain antarmuka dari hasil rekomendasi penerimaan judul skripsi dapat dilihat pada Gambar 4.

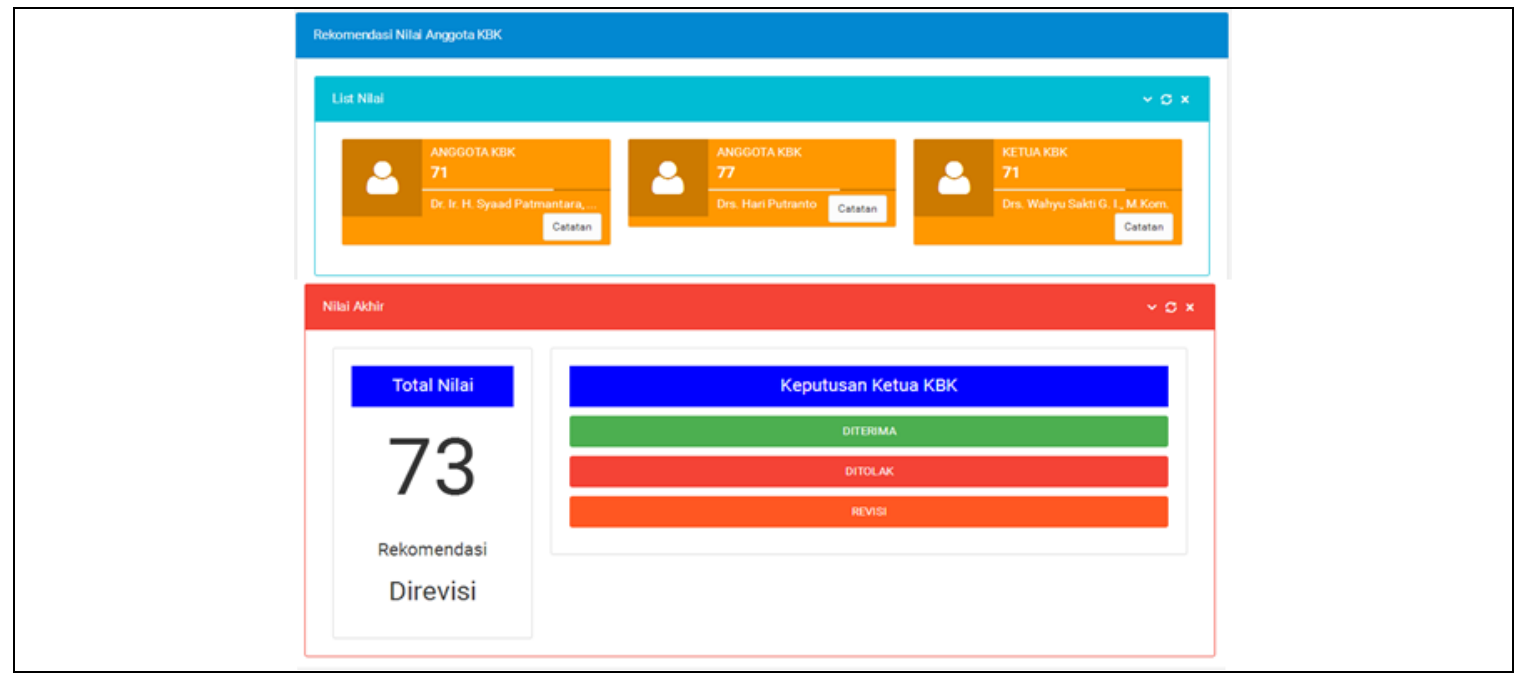

Gambar 4. Desain Antarmuka Rekomendasi Judul Skripsi

\section{Kesimpulan}

Berdasarkan hasil pembahasan di atas, maka dapat disimpulkan sebagai berikut:

- Metode SAW mampu membuat rekomendasi pengambilan keputusan penerimaan judul skripsi.

- Nilai bobot kriteria penerimaan judul skripsi berasal dari masukan user sehingga prioritas kriteria penerimaan judul dapat berbeda-beda. 


\section{TEKNO Jumal Teknologi Elekrto dan Kejuruan}

http://journal2.um.ac.id/index.php/tekno | ISSN 1693-8739

\section{Daftar Rujukan}

Darmastuti, D. 2013. Implementasi Metode SAW dalam Sistem Informasi Lowongan Kerja Berbasis Web untuk Rekomendasi Pencari Kerja Terbaik. (Online), (http://jurnal.untan.ac.id/index.php/justin/article/view/2658/2639), diakses 5 Mei 2017.

Darmawan, D. \& Fauzi, K. N. 2013. Sistem Informasi Manajemen. Bandung: Rosdakarya.

Firdausa. 2015. Metode Simple Additive Weighting (SAW) Untuk Rekomendasi Pemilihan Sekolah Pada Portal Web SMK Negeri Jurusan TIK di Kota Malang. Skripsi tidak diterbitkan, Malang: Penerbit Universitas Negeri Malang.

Firdausa. 2015. Metode Simple Additive Weighting (SAW) Untuk Rekomendasi Pemilihan Sekolah Pada Portal Web SMK Negeri Jurusan TIK di Kota Malang. Skripsi tidak diterbitkan, Malang: Penerbit Universitas Negeri Malang.

Fishburn,P.C.1967." Additive Utilities with Incomplete Product Set: Application to Priorities and Assignments"

Nash, F.J, diterjemahkan oleh La Midjan. 2003. "Sistem Informasi Akuntansi I Pendekatan Manual Pratika Penyusunan Metode dan Prosedur". Bandung : Lembaga Informatika Akuntansi.

Indrawaty, Y.,dkk. 2011. Implementasi Metode SAW pada Sistem Pengambil Keputusan Sertifikasi Guru, (Online), (http://lib.itenas.ac.id/kti/wpcontent/uploads/2013/10/No.-2-Vol.-2-Mei-Agustus-2011-4.pdf), diakses 2 Mei 2107.

Kendall, K.E. \& Kendall, J.E. 2011. System Analysis and Design 8th Edition. New Jersey: Pearson Education.

Kurniasih, D. L. 2013. Sistem Pendukung Keputusan Pemilihan Laptop dengan Metode TOPSIS. (Online), (http://pelita-informatika.com/berkas/jurnal/322.pdf), diakses 28 April 2017.

Munandar, T. A. 2015. Sistem Pendukung Keputusan Pemilihan Siswa Kelas Unggulan pada SMA Negeri 1 Sei Rampah Menggunakan Metode TOPSIS. (Online), (http://pelitainformatika.com/berkas/jurnal/28\%20Tito.pdf), diakses 28 Maret 2015.

Mutaqin, A. Wibawa, A.P., \& Pujianto, U. 2016. Model Analisis Pengambilan Keputusan Peminatan di SMA Menggunakan Metode SAW. Prosiding Seminar IImu Komputer dan Teknologi Informasi, Universitas Mulawarman, (Online), (http://ejournals.unmul.ac.id/index.php/SAKTI/ article/view/163), diakses pada 16 Juni 2017.

Pressman, R. S. 2010. Software Engineering A Practitioner's Approach 7th Edition. New York: McGraw Hill.

Morton, S. (1970). Pendefinisian SPK sebagai "sistem berbasis komputer interaktif.

Sprague, R. H. and Watson H. J., (1993). Decision support systems: putting theory into practice. Englewood Clifts, N.J., Prentice Hall.

Sutikno. 2010. Sistem Pendukung Keputusan Analitic Hierarchy Process untuk Pemilihan Siswa dalam Mengikuti Olimpiade Sains Di Sekolah Menengah Atas. (Online), 


\section{TEKNO Junal Teknologi Elektro dan Kejuruon}

http://journal2.um.ac.id/index.php/tekno | ISSN 1693-8739

(http://eprints.undip.ac.id/24588/1/Makalah_Semnas_ilkom_undip_sutikno.pdf) ,diakses 7 Mei 2017.

Wahono, R. S. 2006. Aspek dan Kriteria Penilaian Media Pembelajaran, (Online), (http://romisatriawahono.net/2006/06/21/aspek-dan-kriteria-penilaian-media-pembelajaran/), diakses 14 Juli 2017.

Wahyudi, R., Wibawa, A.P., \& Pujianto, U. 2016. Rancangan Sistem Rekomendasi Kategori Perusahaan Praktik Industri Menggunakan Algoritma Naïve Bayes. Seminar Nasional Teknologi Informasi dan Multimedia 2016, STMIK AMIKOM Yogyakarta, (Online),(https://ojs.amikom.ac.id/index. php/semnasteknomedia/article/view/1403), diakses pada 18 Maret 2017.

Waspodo, D. H. R. 2015. Integrasi Sistem Informasi Skripsi Dengan Logbook Skripsi pada Jurusan Teknik Elektro UM. Skripsi tidak diterbitkan, Malang: Penerbit Universitas Negeri Malang. 